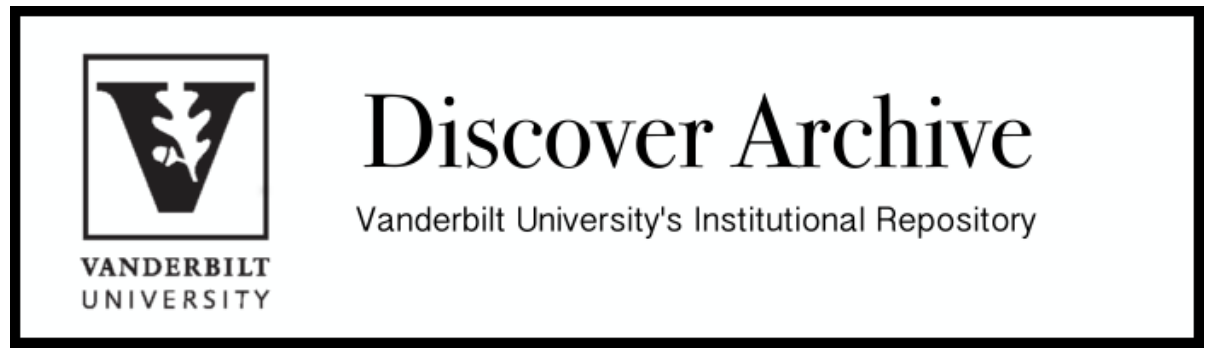

This work was originally published as: W. Kip Viscusi, Natural Disaster Risks: An Introduction - 33 Journal of Risk and Uncertainty 5 (2006). 


\title{
Natural Disaster Risks: An Introduction
}

by

\author{
W. Kip Viscusi *
}

August 21, 2006

Corresponding author: W. Kip Viscusi, email: kip.viscusi@ vanderbilt.edu

* University Distinguished Professor of Law, Economics, and Management, Vanderbilt University, $13121^{\text {st }}$ Ave. South, Nashville, TN 37203. e-mail: kip.viscusi@ vanderbilt.edu. 
Hurricane Katrina generated the largest losses of any natural disaster in the history of the United States. The hurricane hit Florida on August 25, 2005 and Louisiana on August 29. Despite having been downgraded from a Category 4 to a Category 3 hurricane, the storm inflicted unprecedented losses.

This special issue of the Journal of Risk and Uncertainty deals with the implications of catastrophic events for research on risk and uncertainty. What are the consequences of natural disasters? How do individuals and firms respond to such disasters? How do insurers respond, and how should the government respond? Several of these papers will have a strong normative component as they will suggest what actions individuals, firms, and the government should take in anticipation of natural disasters.

The special issue will consist of three parts. The first overview section consists of this introduction, as well as the results of a national survey of disaster risk beliefs and the public's attitudes toward relief efforts. The second part will focus on how people respond to disasters, both in terms of individual housing decisions and insurance company behavior. The third group of papers is more policy-oriented, as it addresses the various policy pitfalls that arise with respect to natural disasters as well as possible strategies for coping with the enormous losses that follow a catastrophic event.

The reason for the salience of catastrophic events is that the losses are huge, often unexpected, and not entirely exogenously determined. The magnitude of loss is influenced to a substantial degree by individuals' exposure to the hazard, the level of personal self-protective behavior, and government policy. Hurricane Katrina led to $\$ 45$ billion in insured losses. ${ }^{1}$ Among Louisianans only, it also had an estimated death toll of

\footnotetext{
${ }^{1}$ Insurance Information Institute, www.iii.org/media/facts/statsbyissue/hurricanes/.
} 
1,577 residents and evacuees. ${ }^{2}$ If these lives are valued at $\$ 7$ million per fatality, which is in line with general labor market estimates of the value of statistical life, the economic cost associated with this mortality loss is $\$ 11.0$ billion. Combining the mortality loss with the value of insured losses leads to a total loss of $\$ 56$ billion.

The total economic value of these losses is almost identical to that associated with the terrorist attack on the World Trade Center and the Pentagon on September 11, 2001. That incident led to $\$ 34.7$ billion in insured losses and an additional 2,976 deaths. ${ }^{3}$ Valuing those deaths at $\$ 7$ million per fatality leads to a total mortality cost of $\$ 20.8$ billion. The combined mortality cost plus insured loss value in this instance is $\$ 55.5$ billion. $^{4}$

The price tag of over $\$ 50$ billion in damages does not exhaust all the economic costs associated with Hurricane Katrina. In the first three weeks following the hurricane, the U.S. Congress appropriated $\$ 75$ billion of disaster assistance. ${ }^{5}$ The Insurance Information Institute estimates that before the relief effort is completed, the government's budgetary cost will be in the $\$ 150$ billion to $\$ 200$ billion range. ${ }^{6}$ Although these expenditures may not be entirely separable from the aforementioned property damage and mortality cost losses, they do indicate the overall catastrophic scale of the impact of Hurricane Katrina.

The next paper in the overview section, "National Survey Evidence on Disasters and Relief: Risk Beliefs, Self-Interest, and Compassion," is by Viscusi and Zeckhauser,

\footnotetext{
${ }^{2}$ Hunter, Michelle. (2006). "Deaths of Evacuees Push Toll to 1,577." New Orleans Times-Picayune, 19 May.

${ }^{3}$ Insurance Information Institute, http://www.iii.org/media/facts/statsbyissue/catastrophes/.

${ }^{4}$ There is some double counting of the mortality cost since some of the insured losses also reflect insurance payments to the families of the deceased.

${ }^{5}$ Insurance Information Institute. (2006). "Hurricane Season of 2005: Impacts on US P/C Insurance Markets in 2006 and Beyond.” Presentation available at http://www.iii.org/media/presentations/katrina/. ${ }^{6}$ Ibid.
} 
who report on original survey results from a representative national sample of over one thousand respondents. To what extent do people perceive the risks of natural disasters accurately, and what role should government relief efforts play? Viscusi and Zeckhauser's paper begins with an exploration of people's risk beliefs and a comparison of those beliefs to individual perceptions of the risks from automobile fatalities and terrorism attacks. Perhaps somewhat surprisingly, over 90 percent of all respondents believe that they face average or below-average risks from all these different sources of risk. These assessments may seem to reflect overoptimism, but the responses are quite sensible due to the highly skewed nature of the risk distribution. The Lorenz curves for various types of risk presented in the article indicate that many risks are highly concentrated - particularly for events such as hurricane risks, which pose few dangers in most states.

The public's perception of the risk of natural disaster risks has both rational and irrational components. A reassuring result is that the regional variations are quite reasonable, as people living in higher-risk states assess higher levels of natural disaster risks. In contrast, terrorism risks, which are more diffuse and less well-understood, do not exhibit much regional variation except for a belief that there is greater likelihood of an attack in a metropolitan area. Personal experience with a particular type of disaster also boosts risk beliefs, as one would expect, but the updating of personal risk beliefs after experiencing a disaster appears to be less pronounced than would be predicted based on a rational Bayesian learning framework.

The respondents' willingness to support aid policies following a natural disaster showed considerable evidence of what the authors call "compassion." A striking 82.2 
percent of all respondents favored government assistance after a natural disaster.

However, if there is substantial moral hazard involved, whereby people have chosen to live in a high-risk area such as a beachfront home, the willingness to support post-disaster aid drops to 37.0 percent. Similarly, if people choose to rebuild in the higher-risk areas of New Orleans, only 36.1 percent of survey respondents are willing to support assistance to such higher-risk areas in the future. Thus, compassion is dampened by efficiency concerns, leading to what the authors call "efficient compassion."

The next two articles present evidence of market responses to disasters, focusing on the housing market and insurance market responses to hurricanes and other natural disasters. The article by Smith, Carbone, Pope, Hallstrom, and Darden, "Adjusting to Natural Disasters," focuses on the second-most costly hurricane in U.S. history, Hurricane Andrew. That hurricane struck Florida in August 1992 and led to $\$ 21.6$ billion in losses in 2005 dollars. $^{7}$

Smith et al. examine housing decisions in the Dade County, Florida area. In analyzing these decisions, they use highly detailed block group level data from the U.S. Census in 1990 and 2000. Thus, they are able to analyze a before-and-after snapshot of the housing market in that particular county, and assess the extent to which the intervening hurricane influenced housing market decisions.

Following Hurricane Andrew, low-income persons moved into the damaged, high-risk areas of Dade County. Such migration is not surprising; damaged areas will have lower property values after a hurricane, and consequently they will be more affordable to those with lower income. However, as noted in the article by Viscusi and Zeckhauser, there will be less public support for a subsequent bailout of damaged high-

\footnotetext{
${ }^{7}$ Insurance Information Institute, http://www.iii.org/media/facts/statsbyissue/catastrophes/.
} 
risk areas should a hurricane strike again. Thus, there will be a difficult conflict between equity and efficiency concerns if the high-risk areas are resettled by the poor.

Smith et al. find that for the middle income respondents, the behavioral response followed standard economic predictions for a reasonable response. In particular, those in the middle income groups exited their residential areas after the hurricane inflicted substantial damage. In contrast, the very wealthy tended to stay put, which the authors suggest may be due to a greater ability to self-insure or to invest in self-protection. Because the housing response to hurricanes is not a simple monotonic function of income, the authors conclude that examining the median response to disasters may be misleading. Rather, one should focus on the distribution of responses, as behavioral adaptations involve a complicated mix of relocation decisions, self-insurance decisions, and self-protection decisions.

The effect of disasters on insurance companies is the focus of the paper by Born and Viscusi. More specifically, they examine the effect on homeowners' insurance using a large sample of firms with observations by state and by year over the 1984-2004 period. They analyze catastrophes of two types, making a distinction between what they term "catastrophes" and what they label as "blockbuster catastrophes." Their threshold for “catastrophes" consists of natural disasters that led to damage of $\$ 25$ million or more. Over the time period they considered, more than 200 hurricanes, tornadoes, earthquakes, and similar natural disasters met this threshold. In addition, they set apart the twenty most costly catastrophic events, which they label "blockbuster catastrophes." Their threshold for distinction as a blockbuster catastrophe is $\$ 1.7$ billion or more in insured losses. 
The possibility of natural disasters should not be unforeseen by insurers. It is common knowledge that California is at risk of earthquakes and that Louisiana, Mississippi, and Texas are susceptible to hurricanes. Thus, what is most problematic from an insurance standpoint are what the authors term "unexpected catastrophes" that are above the average historical level. Blockbuster catastrophes, due to their infrequency, tend to be unexpected.

What are the insurance market consequences of a blockbuster event such as Hurricane Katrina? During the year of the catastrophe, the level of insured losses rises, as does the loss ratio, which is the ratio of losses incurred to the value of premiums earned. However, in the period following a major catastrophe, the loss ratio is below its historical level. Firms raise their premium rates so that the invested premiums during the years in which there is not a blockbuster catastrophe will be available to address the losses when a particularly catastrophic event does occur.

The scale of insurance operations responds to the blockbuster events as well. Some firms go bankrupt as the result of a catastrophe. More importantly, a blockbuster catastrophe increases probability of a firm's exit from the state, and thereby further reduces the number of firms writing coverage in the state. The firms that remain tend to have a very large stake in the insurance market in that state. Catastrophes consequently not only pose problems for individual homeowners, but also for the insurance industry as well.

How then should we structure government policies to deal with catastrophic events? The next series of four articles addresses these policy design issues. The articles also explore the underlying dynamics that may be involved with respect to the interaction 
of individual behavior and the structure of government policies. This interrelationship is a common theme in each of the contributions, as policy makers should recognize that the policy choices they make with respect to post-catastrophe aid will affect the future levels of exposure to risk.

The article by Kousky, Luttmer, and Zeckhauser, "Private Investment and Government Protection," focuses on the interdependence of private investment responses to the level of government protection. The government and the private investors are involved in an interdependent game that may lead to less than ideal outcomes. As was documented in the paper on Hurricane Andrew by Smith et al. in this issue, private investment does respond to the level of government protection. Similarly, government protection responds to private assets. The authors give the example of how California increased the safety of levees to protect the development that took place in the Sacramento-San Joaquin Valley. The choices made by private investors and the government are consequently quite interdependent. In designing government policies, one must account for how private investment and individual protective behavior will respond to the policy structure and relief effort.

The authors explore questions such as whether the government should permit New Orleans to be rebuilt based on centralized individual decision-making. If individuals are given complete freedom to invest in the high-risk areas, then that flexibility will generate an impetus for increased government protection of these areas once the investment has taken place. Kousky et al. conclude that there may be multiple equilibria, and there is no assurance that societal choices will result in an efficient equilibrium outcome. 
While it is always desirable to use benefit-cost analysis as our policy guide, our risk exposure reference point for calculating these benefits and costs will be affected by the government's policy choices. Our societal objective should be to maximize social welfare-which may not be the same thing as following benefit-cost guidelines, unless those guidelines also account for the interdependence of government protection and private investment responses.

The article by Kunreuther and Pauly, "Rules Rather than Discretion: Lessons from Hurricane Katrina," likewise is concerned with this interdependence and focuses on possible policy remedies to address the inefficiencies that may arise. In the authors' view, people do not generally self-insure due to a variety of behavioral irrationalities, such as underestimating the likelihood of a catastrophic event or its effect on their wellbeing. Because of the absence of adequate insurance, there will be substantial pressures for relief aid after a catastrophe. Self-protection likewise will be hampered by irrationality. The authors document this irrationality through an exploration of the historical responses to flood risks and the inadequate levels of insurance that people have purchased with respect to such hazards. Their research consequently builds on the decades of previous research on floods by Kunreuther et al (1978). ${ }^{8}$

How then can policy makers cope with the inefficiencies that will arise from inadequate safety-related behavior by individuals coupled with pressures for inefficient disaster relief once the disasters have occurred? Kunreuther and Pauly propose several possible remedies. Most important is that they urge us to formulate our policy with respect to disasters before disasters have occurred. In particular, the main concern should

\footnotetext{
${ }^{8}$ Kunreuther, Howard C. et al. (1978). Disaster Insurance Protection: Public Policy Lessons. New York: Wiley.
} 
be to take steps prior to the catastrophic event to ensure efficient behavior on the part of those exposed to the risk, and on the decisions of those who are not yet exposed, but who could be depending on their locational choice. One policy the authors recommend is that there must be rules, not discretion, governing the rebuilding of risky areas. Zoning restrictions are one example of such rules. In addition, they recommend mandatory disaster insurance so that individuals will be required to have insurance coverage. Moreover, by paying the premiums for disaster insurance, people will be more cognizant of the financial risks that their locational decisions entail. In short, Kunreuther and Pauly recommend that people internalize the financial risks of disasters ex ante, which will foster much more efficient decisions than those that result under the current policy frameworks.

In their paper, "Planning for Natural Disasters in a Stochastic World," Lave and Apt provide a series of guidelines that are likewise governed by economic efficiency concerns. As with Kunreuther and Pauly, they advocate strict zoning coupled with mandatory insurance for those exposed to natural hazards. They also advocate application of a benefit-cost framework to the design of disaster policies, which is in the same vein as the two earlier articles.

Two of the most distinctive policy recommendations in the article by Lave and Apt are the potential role of information and the authors' guidelines for policy analysis. With respect to information, the authors recommend that the government provide more information to people regarding the risks they face. A general theme throughout the papers in this issue is that people do not have well-formulated, accurate risk beliefs concerning the low-probability, high-loss events associated with disasters. Unlike fire 
hazards to dwellings— which are better understood, according to Lave and Apt—-the risks from disasters such as floods and hurricanes are more the subject of guesswork. Government information provision could remedy this inadequacy and foster more rational risk taking decisions.

Lave and Apt also have a recommended emphasis for government policy. In their view, there is little that can be done to address large disasters, which tend to be unexpected and infrequent. As a result, the government should focus more on information provision regarding small and moderate natural disasters. Thus, in terms of scale, the emphasis in policy making should be to address what Born and Viscusi call catastrophes rather than blockbuster catastrophes. Because most natural disasters are on a small or moderate scale, Lave and Apt's policy recommendations would also address a great deal of the financial losses associated with disasters as well.

The final paper in this volume, "Analyzing Disaster Risks and Plans: An Avian Flu Example," by Fischhoff et al., deals with conceptualization of the possible avian flu disaster. In 2005 and 2006, substantial fears were aroused concerning the potential risk of avian flu in the United States. As with hurricanes, an avian flu epidemic would be a natural disaster. However, the avian flu risk is slower-moving than many other types of disasters and consequently has given policy makers greater time to develop a policy response. Avian flu also poses highly diffuse risks that may not materialize, much like a tropical depression which gathers strength offshore but then gives out before hitting land.

What Fischhoff and his coauthors explore is how policy makers should structure their analyses of such potential disasters. In their view, there are two general approaches that are competing frameworks for analysis. The first consists of computable models 
such as a statistical decision theory model in which there is an attempt to assign probabilities to the branches of the chance forks and payoff values to the tips of the decision tree. The alternative approach is a more qualitative exploration of possible scenarios that might develop as a result of avian flu risks.

The authors suggest that these two dichotomous approaches be integrated. Thus, one would use structured scenarios to explore the extent to which the computable models capture the key elements of the decision problem. Then the model can be revised to incorporate the nuances revealed by the structural scenarios. As with several other articles in this special issue, the authors are very concerned with the behavioral dependency linkages that arise in the decision analysis problem. In their view, by exploring structured scenarios the analysts will be able to better understand which behavioral linkages arise and those linkages' importance to how the decision analysis problem can be framed.

The authors conclude that the more narrowly-framed current policy approach may be missing some potentially superior policy options. Thus, the United States has pursued a vaccine and antiviral investment strategy to combat avian flu. What the authors suggest is that one would be led to a different policy mix after working through the ramifications of the scenario that examines the pandemic actually hitting the United States. Approaching the policy choice by conceptualizing such a scenario suggests that a superior policy approach would include a larger investment in antibiotics to treat secondary infections, as well as more investment in medical care than the current strategy dictates. Fischhoff et al. conclude that the triangulation process involving structured 
scenarios and computable models can lead to a more sound policy decision process than use of either of these approaches alone.

The government's response to Hurricane Katrina has garnered very little praise. In commenting on Hurricane Katrina and the relief effort, filmmaker Spike Lee observed: "What happened in New Orleans was a criminal act." 9 During the rescue effort, it became evident that most of the people who sought refuge in the Louisiana Superdome or who perched on rooftops awaiting rescue were black. As many of the articles in this issue demonstrate, the subjects of race and class are intertwined in a complex manner with respect to post-disaster policies.

Allowing substantial discretion with respect to the rebuilding effort, which has been the policy approach to date in New Orleans, will lead people to rebuild in very highrisk areas. Because the high-risk areas in New Orleans have lower property values, the people occupying them will be disproportionately minority and poor. In addition, without rigid zoning restrictions or much better prevention efforts to reduce risks from hurricanes and subsequent flooding, the inhabitants of high-risk areas may again face substantial prospective losses in the future. Required insurance protection could reduce the problems that will arise if there is a repetition of a disaster of the magnitude of Hurricane Katrina.

In the absence of self-insurance, zoning restrictions, or other preventive actions taken before the next hurricane, the post-disaster outcome after a repetition of Hurricane Katrina could have more dire consequences than Hurricane Katrina did, and the same levels of government aid and public support may not be as readily available. With the exception of the non-Hispanic black respondents in Viscusi and Zeckhauser's survey, an

\footnotetext{
${ }^{9}$ Lee, Felicia R. (2006). “After the Flood, the Reckoning.” The New York Times, 3 August, B1.
} 
overwhelming percentage of the U.S. population does not favor repeated aid to people who rebuild in high-risk areas. Whether this public sentiment will persist after a future catastrophic event becomes a reality rather than a hypothetical possibility is not clear, but it does suggest that there needs to be greater government attention to fostering efficient behavior before the advent of another major catastrophe. 